\title{
Effect of Infla-Kine supplementation on the gene expression of inflammatory markers in peripheral mononuclear cells and on C-reactive protein in blood
}

\author{
Nina A. Mikirova', Santosh Kesari ${ }^{2}$, Thomas E. Ichim ${ }^{3 *}$ and Neil H. Riordan ${ }^{4}$
}

\begin{abstract}
Background: Chronic inflammation is a predisposing factor to numerous degenerative diseases including cancer, heart failure and Alzheimer's disease. Infla-Kine is a natural supplement comprised of a proprietary blend of Lactobacillus fermentum extract, burdock seed (arctigenin), zinc, alpha lipoic acid, papaya enzyme and an enhanced absorption bio-curcumin complex $\left(\mathrm{BCM}-95^{\circledR}\right)$.

Methods: Infla-Kine was administered twice daily to 24 health volunteers for 4 weeks. Quantitative RT-PCR was used to assess mRNA transcripts of IL-1 b, IL8, IL-6, NF-kB, and TNF-a from peripheral blood mononuclear cells (PBMC). C reactive protein (CRP) was measured from serum. Additionally, quality of life questionnaires were employed to assess general feeling of well-being. Assessments were made before treatment and at conclusion of treatment (4 weeks).

Results: As compared to pre-treatment, after 4 weeks, a statistically significant reduction of IL8, IL-6, NF-KB, and TNF-a transcripts was observed in PBMC. Furthermore, reduction of IL-1b transcript and serum CRP was observed but did not reach statistical significance. Quality of life improvements were most prevalent in muscle and joint pains.

Conclusions: Overall, our data demonstrate that twice daily administration of Infla-Kine for 4 weeks reduces inflammatory markers and quality of life in healthy volunteers.
\end{abstract}

\section{Background}

Chronic inflammation is associated with persistent, yet low grade, activation of various bodily defense factors which often results in deleterious effects to the host. In a healthy immune response inflammatory mediators, such as cytokines, are upregulated in response to a pathogen. Subsequent to clearance of the pathogens the factors are downregulated. In contrast, in chronic inflammation the same molecular mediators that are used to protect the host against pathogens often become the cause of pathology due to their chronic production. For example, TNFalpha is a cytokine produced by innate immune cells such as macrophages and is involved in host responses to

\footnotetext{
*Correspondence: thomas.ichim@gmail.com

${ }^{3}$ Immune Advisors LLC, San Diego, CA, USA

Full list of author information is available at the end of the article
}

various bacteria such as tuberculosis. During the natural course of an immune response, subsequent to clearing of mycobacterium tuberculosis, production of TNF-alpha subsides. In contrast, in conditions such as obesity, excess adipocytes directly secrete TNF-alpha [1], as well as produce agents that induce production of TNF-alpha such as HMGB-1 [2, 3]. Although originally correlative studies existed between obesity and comorbidities such as Type 2 diabetes and cardiovascular diseases, the era of cellular and molecular medicine has led to specific causal effects of chronic inflammation in evolution of pathologies. In the example of Type 2 diabetes, TNF-alpha have been shown to be directly associated with induction of insulin resistance, in part through suppression of the insulin receptor substrate component of insulin receptor signaling [4-7]. In the example of cardiovascular disease, inflammatory mediators, such as, TNF-alpha [8, 9], IL-1 
beta [10], and IL-6 [11], have been shown to be directly inhibitory to endothelial progenitor cells (EPC). EPC are known to play a fundamental role in regenerating vascular endothelium and EPC levels negatively correlate with cardiovascular risk factors $[12,13]$.

The prospect of a natural supplement reducing chronic inflammation has potential in the treatment of numerous conditions in which inflammation plays a major pathogenic role. In addition conditions classically associated with chronic inflammation such as diabetes and cardiovascular disease, chronic inflammation has been shown to be important in other conditions. For example, in cancer patients, chronic inflammatory conditions are associated with stimulation of pathological angiogenesis [14-17], as well as immune suppression [18]. In dialysis patients, inflammatory mediators are believed to play a role in the overall shorter survival of patients [19-23]. Even psychiatric conditions such as panic disorder have been reported to possess an inflammatory element [24, 25].

Infla-Kine is a commercially available nutraceutical supplement comprised of a proprietary blend of Lactobacillus fermentum (LF) extract, burdock seed (arctigenin), zinc, alpha lipoic acid, papaya enzyme and an enhanced absorption bio-curcumin complex (BCM-9 $5^{\circledR}$ ). Lactobacillus fermentum extract has proven health benefits [26]. It is natural immune booster and has been shown to trigger a cascade of events that help regulate the immune system, making it stronger and more efficient. In addition, the administration of LF was associated with significant mobilization of cells expressing hematopoietic stem cell markers [27], which is extremely important for health, as numerous studies demonstrate a direct, positive correlation between the number of circulating stem cells and health, wellness and regenerative capabilities [28].

The current study assessed whether levels of inflammatory mediators were affected by administration of Infla-Kine for 4 weeks in healthy volunteers. The results support the use of this natural-based food supplement for modulation of chronic inflammatory states, and thus potentially reducing a variety of health risks.

\section{Methods}

\section{Recruitment of subjects}

Twenty-four subjects (20 women and 4 men) were recruited for a short-term (4 weeks) study in order to assess the effect of Infla-Kine supplementation on gene expression of inflammatory cytokines in PBMCs and serum $\mathrm{C}$-reactive protein. Subjects were chosen among the employees of the Riordan Clinic and provided written informed consent to participate in the study. The research was in compliance of the declaration of Helsinki and approved by the Institutional Review Board of Riordan Clinic.

All participants were in good health as determined by a medical history and clinical laboratory tests. Subjects fulfilled the following criteria:

1. No history of chronic disease.

2. No antibiotic use for 2 weeks before the beginning of the study.

3. Nonsmoking.

4. No drugs or nonsteroidal inflammatory drugs 2 weeks before and during the study.

Subjects with Type 1 diabetes mellitus, autoimmune diseases, malignant diseases, and infectious diseases were excluded from the study. Participants maintained their usual habits including physical, sleeping habits and diet during the study.

After enrollment, participants took at least 2 capsules of supplement Infla-Kine daily for month. Blood samples were drawn at the beginning of the study and at the end of the study.

\section{Isolation of PBMC}

Whole blood was collected by venipuncture into heparinized tubes. For PBMC collection, blood was diluted 1:1 with phosphate buffered saline (PBS), layered on top of Ficoll-Paque Plus (Amersham Biosciences), and centrifuged at $400 \mathrm{~g}$ for $30 \mathrm{~min}$ at $4{ }^{\circ} \mathrm{C}$. PBMC were then removed from the plasma-Ficoll interface and rinsed twice with PBS.

CRP in blood serum (collected by venipuncture and centrifugation) was measured by a licensed and certified medical Bio-Center Laboratory of the Riordan Clinic (CLIA 17D0648333) by standard procedure.

\section{RNA extraction and qRT-PCR}

After separation of PBMCs, $1 \mathrm{~mL}$ of TriReagent (SigmaAldrich, Hercules CA) was added for RNA extraction following manufacturer's instructions. Total RNA quality and quantity was evaluated using the Nanodrop ND-2000 (Thermo Scientific, Pittsburg PA) and subsequently converted to cDNA using the iScript RT supermix in the CFX96 Real-Time PCR Detection System (Bio-Rad, Hercules, CA, USA). cDNA was than quantified using the Nanodrop ND-2000 and a total of 250 ng were used to analyze gene-specific oligonucleotide primers (Table 1) with the SsoAdv Universal SYBR GREEN Kit. A dissociation curve was run at the end of the reaction to ensure that only one amplicon was formed and that the amplicons denatured consistently in the same temperature 
Table 1 Oligonucleotide primers and PCR conditions for inflammatory response genes

\begin{tabular}{|c|c|c|c|}
\hline Genbank access. \# & Symbol and description & Primers & $\mathrm{qPCR}^{\mathrm{a}}\left({ }^{\circ} \mathrm{C}\right)$ \\
\hline NM_000576.2 & $\begin{array}{l}\text { IL1 } \beta \\
\text { Interleukin } 1 \text { beta }\end{array}$ & $\begin{array}{l}\text { HsIL1BF: ggagaatgacctgagcacct } \\
\text { HsIL1BR: ggaggtggagagctttcagt }\end{array}$ & 56 \\
\hline NM_000584.3 & $\begin{array}{l}\text { CXCL8 } \\
\text { Interleukin } 8\end{array}$ & $\begin{array}{l}\text { HsIL8F: cagttttgccaaggagtgct } \\
\text { HsIL8R: acttctccacaaccctctgc }\end{array}$ & 58 \\
\hline NM_000594.3 & $\begin{array}{l}\text { TNF } \\
\text { Tumor necrosis factor }\end{array}$ & $\begin{array}{l}\text { HsTNFF: gtcaacctcctctctgccat } \\
\text { HsTNFR: ccaaagtagacctgcccaga }\end{array}$ & 57 \\
\hline NM_001165412 & $\begin{array}{l}\text { NFkB } \\
\text { Nuclear factor kappa B }\end{array}$ & $\begin{array}{l}\text { NFkBF: gcacgacaacatctcattgg } \\
\text { NFkBR: tcccaagagtcatccaggtc }\end{array}$ & 58 \\
\hline NM_001017.2 & $\begin{array}{l}\text { RSP13 } \\
\text { Ribosomal protein } 13\end{array}$ & $\begin{array}{l}\text { RPS13F: cgaaagcatcttgagaggaaca } \\
\text { RPS13R: tcgagccaaacggtgaatc }\end{array}$ & 57 \\
\hline NM_000600.3 & $\begin{array}{l}\text { IL6 } \\
\text { Interlukin } 6\end{array}$ & $\begin{array}{l}\text { HsIL6F: agtcctgatccagttcctgc } \\
\text { HsIL6R: aagctgcgcagaatgagatg }\end{array}$ & 56 \\
\hline
\end{tabular}

a Initial denaturation at $98^{\circ} \mathrm{C}$ for $30 \mathrm{~s}$, followed by forty cycles of denaturation at $95^{\circ} \mathrm{C}$ for $10 \mathrm{~s}$, annealing for $15 \mathrm{~s}$ (at temperature given) and extension at $60^{\circ} \mathrm{C}$ for $15 \mathrm{~s}$

range for every sample. The cDNA levels were normalized against housekeeping gene ribosomal protein 13 (RSP13).

\section{Health questionnaire}

A multi-item scale based questionnaire was used which included symptoms (fever, chills, headaches, loss of appetite, joint pain, joint stiffness, constipation, diarrhea, bloating), a global health improvement (overall improvement of physical conditions) and overall improvement of the quality of life. The range in score was from 0 to 4 for symptoms and from 1 to 7 for overall improvement.

Signs and symptoms were allocated intensity scores of 0 (never or almost never have the symptom); 1 (occasionally have it, mild symptoms); 2 (occasionally have it, severe symptoms); 3 (frequent have it, mild symptoms); 4 (frequently have it, severe symptoms). The overall improvement of the physical conditions and quality of life was rated with a difference of $1-7$ points, 1 representing a small change and 7 representing the largest improvement.

In efficacy analysis, the symptom intensity scores were considered as quantitative variables and values were calculated as the percentage of the participants who had the symptom with certain score to total number of participants.

\section{Statistical analysis}

The analysis and comparisons of mRNA expression levels were carried out using the Kaleidagraph (Synergy Software, Reading PA, USA) and Systat Software (San Jose, CA, USA) statistical software. Data are presented as mean $\pm \mathrm{SD}$. Pre and post treatment comparison was performed using paired $t$ tests and ANOVA. Differences in mean values were considered significant at the level of $95 \%(p<0.05)$. Outliers in gene expression data were removed based on the interquartile range test. The $2^{-\Delta \Delta \mathrm{Ct}}$ method was used to calculate differences in gene expression.

\section{Results}

Baseline demographics

The sample size was 24 subjects ( 4 men and 20 women) without any systemic diseases. The average age of participants was $48.4 \pm 14.7$ years old. There was trend towards adiposity in group of participants (higher than normal range of BMI $30.9 \pm 8.1$ and elevated cholesterol $210.0 \pm 56.4 \mathrm{mg} / \mathrm{dL}$ at normal level $<200 \mathrm{mg} / \mathrm{dL})$. Most of the participants had inflammation and increased level of CRP. In average CRP was $3.95 \pm 3.85 \mathrm{mg} / \mathrm{L}$ at normal level $<2 \mathrm{mg} / \mathrm{L}$ (interquartile range IQR 1.1-6.9 mg/L). Eight subject had CRP three times higher than normal range and the maximum level of CRP reached $13.8 \mathrm{mg} / \mathrm{dL}$.

\section{Effect of supplementation on gene expression of inflammatory markers}

Blood samples were extracted, and levels of mRNA expression from isolated peripheral blood mononuclear cells (PBMC), from healthy volunteers before and after administration of Infla-Kine for 4 weeks. As shown in Fig. 1 and Table 2, PBMC mRNA expression levels of various cytokines during the time course of the study. Data in Table 2 demonstrate the average with SD of the expressions of IL-1b, IL8, IL-6, NF-kB, and TNF- $\alpha$ before and after intervention. Outliers in gene expression data were removed based on the interquartile range test. The last column in Table 2 shows the $\mathrm{p}$ values calculated by paired $\mathrm{t}$ test. It was observed that IL-8, IL-6, TNF- $\alpha$ and NF- $\kappa$ B showed statistically significant changes after 4 week administration of Infla-Kine. For the cytokine IL-1b gene expression level decreased, but did not reach statistical significance $(\mathrm{p}<0.13)$. According to our data, the gene expression of inflammatory cytokines 


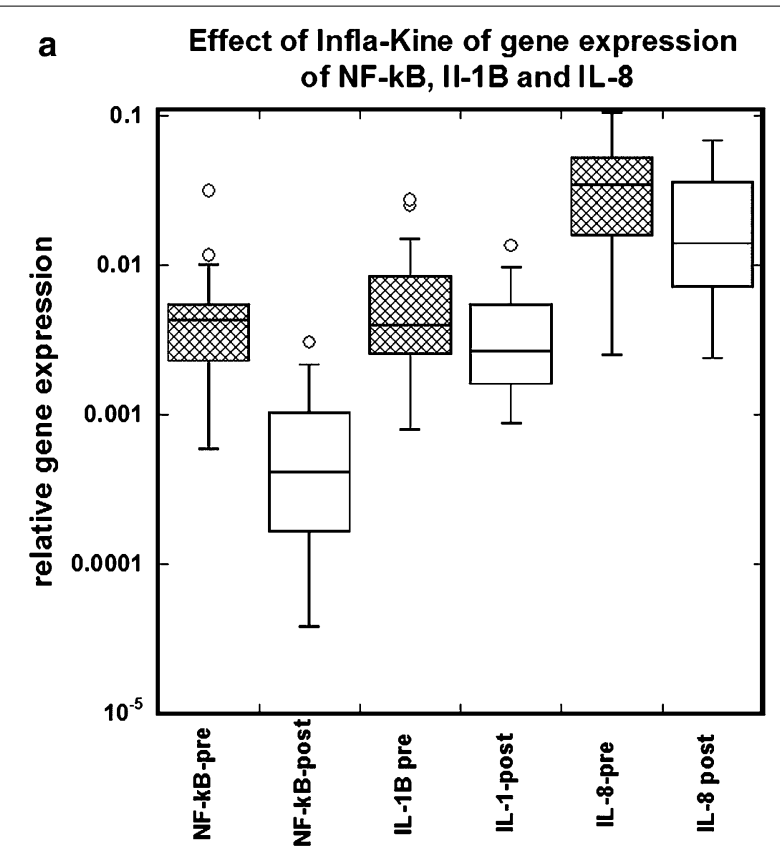

b Effect of Infla-Kine on gene expression of II-6 and TNF

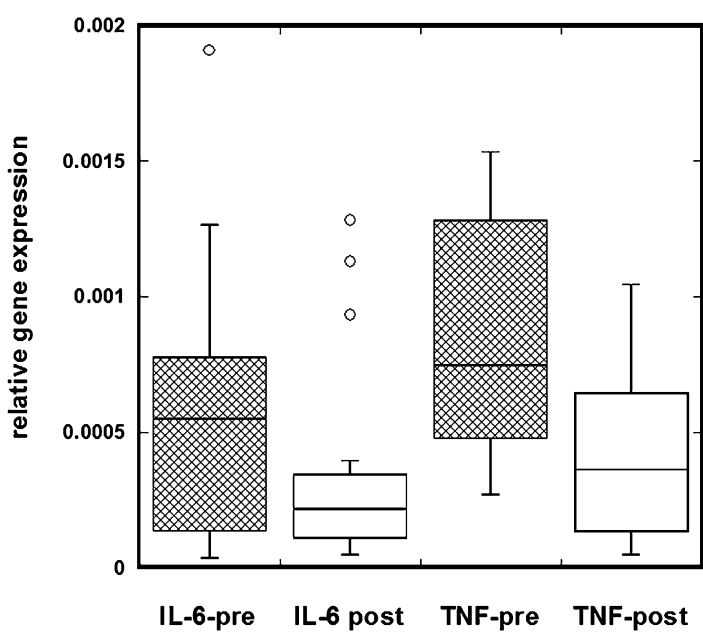

Fig. 1 Effects of 4 week Infla-Kine supplementation on PBMC inflammatory gene expression. Gene expression was assessed by RT-PCR as indicated in materials and methods from patient PBMC prior to initiation of Infla-Kine administration (Pre) and 4 weeks after (Post). Relative gene expression was quantified based on housekeeping gene control. a Depicts NF-kappa B, IL-1 beta and IL-8 expression, whereas $\mathbf{b}$ depicts IL-6 and TNF-alpha expression

was downregulated 1.6 times for IL-6, 1.4 times for TNF- $\alpha$, 2.0 times for IL- 8 and 1.4 times for IL-1b. The gene expression of transcriptional factor NF- $\mathrm{kB}$ was downregulated 5.6 times as the result of intervention.

\section{Effect of Infla-Kine supplementation on CRP}

In addition to the gene expression of pro-inflammatory cytokines in PBMCs, we measured the levels of
Table 2 PBMC mRNA expression levels of various cytokines and transcriptional factors before and after intervention

\begin{tabular}{lllllll}
\hline & \multicolumn{2}{l}{ Before } & & & After & \multicolumn{1}{c}{ p value (one tail) } \\
\cline { 2 - 3 } & Average & SD & & Average & SD & \\
\hline NF-KB & 0.00388 & 0.00237 & 0.00068 & 0.00074 & 0.0001 \\
IL1B & 0.00483 & 0.00388 & 0.00348 & 0.00239 & 0.13 \\
IL8 & 0.03506 & 0.02595 & 0.01735 & 0.01578 & 0.003 \\
TNF-a & 0.00097 & 0.00088 & 0.00068 & 0.00112 & 0.004 \\
IL-6 & 0.00057 & 0.00053 & 0.00036 & 0.00037 & 0.006 \\
\hline
\end{tabular}

C-reactive protein (CRP), an acute phase protein, which is a sensitive systemic marker of inflammation and acutephase reactions. CRP values may increase by several folds by de novo hepatic synthesis regulated by pro-inflammatory cytokines, especially interleukin-6 [29]. A major CRP response is observed in infection and sepsis, various auto-immunopathies, tissue necrosis, trauma, and neoplasia [30].

Data presented in Table 3 show the measured CRP levels before and after intervention and the body mass indexes (BMI) of participants. The subjects recruited in this study tended toward obesity, as normal BMI is in range 18.5-24.9; for overweight subjects the range is 25-29.9 and in obese subjects 30.0-34.9. Increased level of BMI showed correlation $(r=0.7)$ with the levels of the inflammation marker CRP (Fig. 2). The average values of CRP before after supplementation with $\mathrm{p}$ values (paired $t$ test, one-tail) are presented in Table 4 . The data are shown for all subjects and for subjects with initial CRP higher than normal range (CRP > $2 \mathrm{ng} / \mathrm{mL}$ ). The average values of CRP for both groups were reduced, but the difference did not reach statistical significance ( $p$ values 0.17 and 0.19 ).

The percentage of difference in CRP measured pre and post intervention is shown for all subjects in Fig. 3a and for subjects with abnormal initial levels of CRP in Fig. 3b. Negative values demonstrate the improvement in the CRP concentrations after intervention and positive values-increase in these values. According to our data, treatment during 1 month by oral supplement Infla-Kine was associated with a decrease in CRP levels in $62 \%$ of all participants and in $71.4 \%$ of participants with CRP higher than upper normal level (CRP > $2 \mathrm{ng} / \mathrm{mL}$ ).

\section{Improvement in health questionnaire}

The calculated values are presented in Table 5 and showed the percentage of participants who had any of the listed symptoms sorted according to the score (0-4) and the percentage of participants. Subjects who were on Infla-Kine supplementation also declared at the end of 
Table 3 Patient level CRP data

\begin{tabular}{|c|c|c|c|c|c|c|c|}
\hline Subjects & BMI & CRP-pre & CRP-post & Subjects & BMI & CRP-pre & CRP-post \\
\hline 1 & 30.9 & 6.2 & 8.74 & 13 & 26.6 & 1.89 & 1.61 \\
\hline 2 & 23.9 & 0.48 & 0.37 & 14 & 28 & 1.27 & 1.45 \\
\hline 3 & 32.7 & 2 & 1.64 & 15 & 28.5 & 0.62 & 0.55 \\
\hline 4 & 27.8 & 2.18 & 2.98 & 16 & 18.9 & 0.53 & 0.58 \\
\hline 5 & 43.9 & 13.76 & 18.5 & 17 & 24 & 0.33 & 0.33 \\
\hline 6 & 44.4 & 7.12 & 3.74 & 18 & 23 & 1.18 & 1.1 \\
\hline 7 & 29.6 & 0.67 & 0.91 & 19 & 28.7 & 6.01 & 5.95 \\
\hline 8 & 18.5 & 0.6 & 0.16 & 20 & 34 & 9.58 & 6.86 \\
\hline 9 & 31.4 & 3.7 & 2.42 & 21 & 29 & 8.01 & 4.09 \\
\hline 10 & 18.8 & 2 & 1.5 & 22 & 26 & 4.13 & 2.52 \\
\hline 11 & 40 & 2.09 & 1.96 & 23 & 30.5 & 1.2 & 0.48 \\
\hline 12 & 46.6 & 8.67 & 5.77 & 24 & 34.4 & 10.6 & 11.35 \\
\hline
\end{tabular}

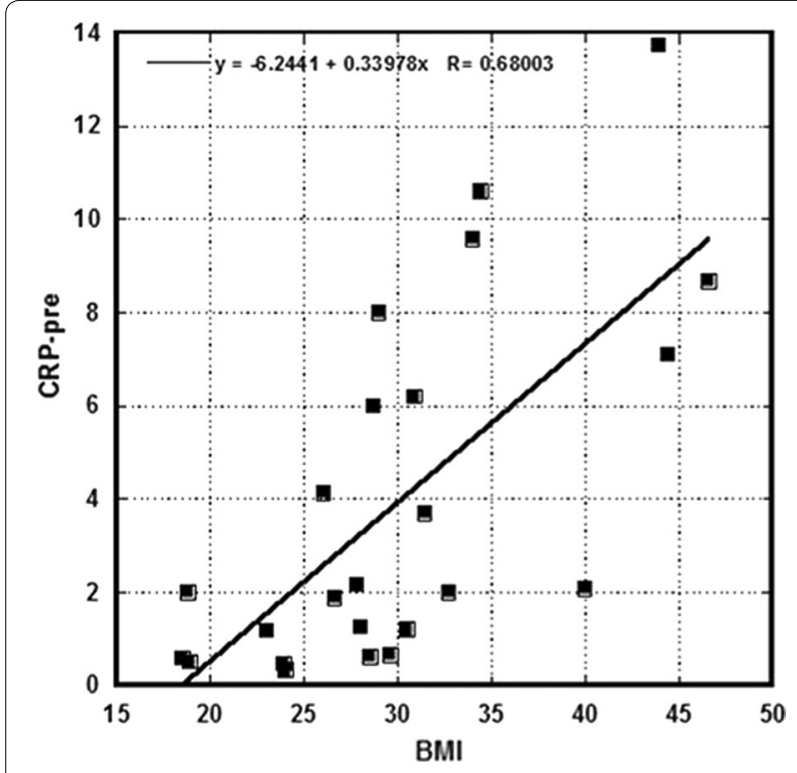

Fig. 2 Correlation of CRP and body mass index prior to intervention. CRP and BMI were quantified as described in materials and methods. A positive correlation was observed between CRP and BMI

Table 4 Summary of CRP levels before and after treatments

\begin{tabular}{lllll}
\hline & CRP & Pre & Post & p value \\
\hline All subjects & Average & 4.04 & 3.65 & 0.17 \\
& SD & 3.91 & 4.38 & \\
Subjects with CRP $>2 \mathrm{ng} / \mathrm{mL}$ & Average & 6.14 & 5.58 & 0.19 \\
& SD & 3.70 & 4.71 & \\
\hline
\end{tabular}

the study the improvement of the physical conditions and quality of life on scale from 1 (poor) to 7 (very good). 70\% of patients declared improvement in physical conditions and the quality of life at the level higher than four. The highest level of improvement $15-20 \%$ was in conditions of muscle and joint stiffness and joint pain. $10 \%$ indicated the improvement in the energy level and constipation. Only $5 \%$ of the subjects had complaints of worsening conditions.

\section{Discussion}

The effects of the Infla-Kine supplementation on gene expression and transcriptional factor modulation in peripheral blood mononuclear cells from 24 subjects were determined. Participants received two capsules per day for 4 weeks. The expression profile of several genes related to the inflammation was quantified by real time RT-PCR. In addition, C-reactive protein was measured at the beginning and the end of intervention.

Many subjects in this study tended toward obesity, and showed typical symptoms of adiposity, including abnormally high levels of the inflammation marker CRP. Our data demonstrated a correlation between CRP and BMI $(r=0.7)$ before intervention. This is consistent with observations in the literature that inflammation levels are increased in overweight and obese subjects [31, 32]. According to the other studies, conditions associated with adiposity are also accompanied by changes in PBMC gene expression favoring inflammation [33]. Pro-inflammatory cytokines such TNF- $\alpha$ and IL-6 are overexpressed in obese subjects, as is nuclear factor kappa-light-chain-enhancer of activated B cells (NF$\kappa \mathrm{B})$, the transcription factor that controls many genes 


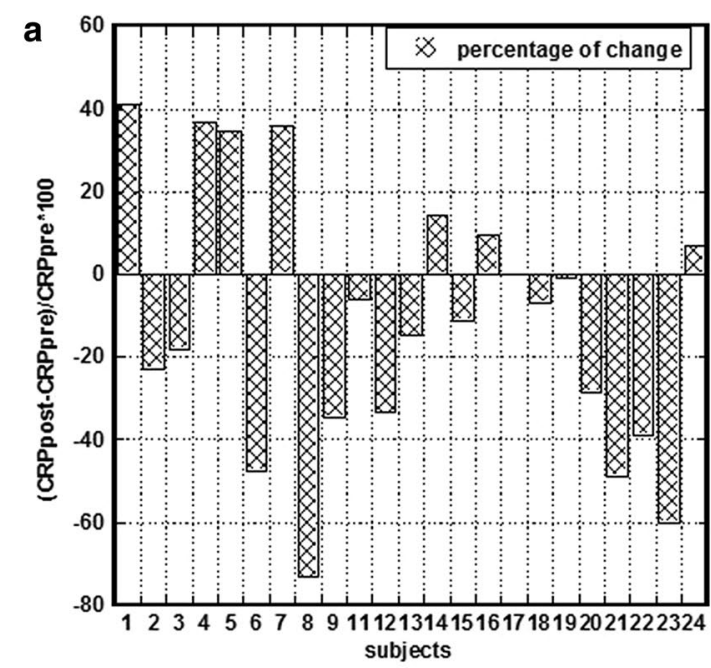

b

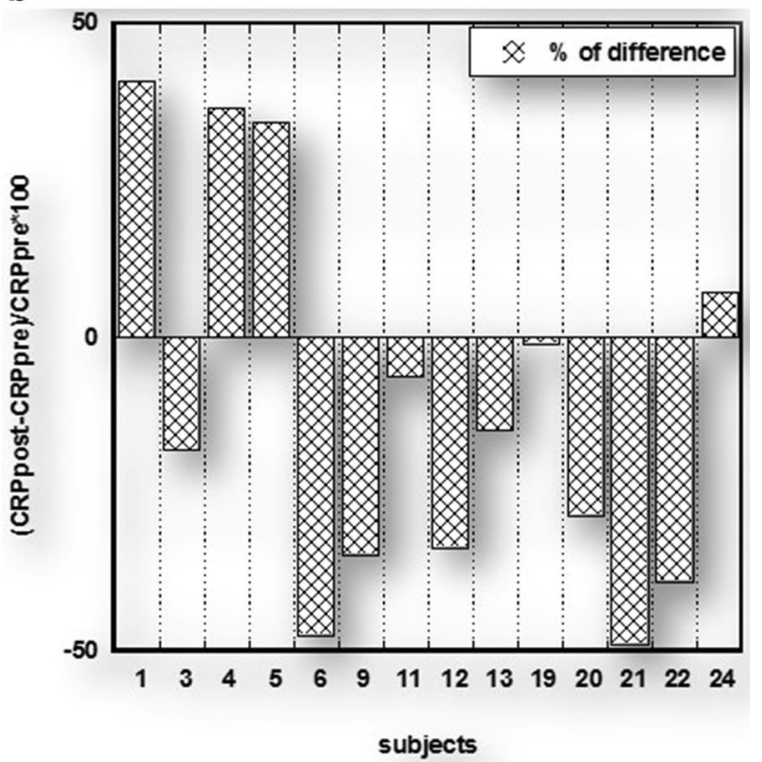

Fig. 3 Modification of CRP levels by 4 week Infla-Kine supplementation. The percentage of difference in CRP measured pre and post intervention is shown for all subjects in $\mathbf{a}$ and for subjects with abnormal initial levels of CRP in $\mathbf{b}$. Negative values demonstrate the improvement in the CRP concentrations after intervention and positive values-increase in these values

associated with inflammation [34]. Moreover, subjects with adiposity have reduced serum levels of the antiinflammatory cytokines [35].
According to our study, gene expression of pro-inflammatory cytokines was significantly affected by Infla-Kine supplementation. IL-8, IL-6, and TNF- $\alpha$ showed statistically significant downregulation during the time frame of the study. For the cytokine IL-1b the gene expression levels was decreased, but did not reach statistical significance. The supplementation caused downregulation of transcriptional factor NF- $\mathrm{kB}(\mathrm{p}<0.0001)$. NF- $\mathrm{kB}$ is considered a prototypical pro-inflammatory signaling pathway, largely based on the activation of NF- $\mathrm{kB}$ by proinflammatory cytokines such as IL-1 and TNF-a, and the role of NF- $\mathrm{KB}$ in the expression of other pro-inflammatory genes including cytokines, chemokines, and adhesion molecules, which has been extensively reviewed elsewhere [36].

Another measured parameter was CRP, which directly correlates with disease activity in many diseases and can contribute to disease progression through a range of pro-inflammatory properties. Being an exquisitely sensitive marker of systemic inflammation and tissue damage, CRP is very useful in screening for organic disease, monitoring treatment responses, and detecting infection.

Our data demonstrated that the intervention by supplementation showed positive effect on the concentrations of CRP. The treatment by oral supplement Infla-Kine during 1 month was associated with a decrease in CRP levels in $62 \%$ of all participants and in $71.4 \%$ of participants with CRP higher than upper normal level (CRP > $2 \mathrm{ng}$ / $\mathrm{mL}$ ).

At the end of the study each participant filled the questionnaire, which included symptoms (fever, chills, fatigue, headaches, loss of appetite, joint pain, joint stiffness, constipation, diarrhea, bloating), a global health improvement (overall improvement of physical conditions) and overall improvement of the quality of life. $70 \%$ of patients declared improvement in physical conditions and the quality of life at the level higher than four on scale from 1 to 7. The highest level of improvement was in conditions of muscle and joint stiffness and joint pain.

\section{Conclusion}

Infla-Kine, a commercially-available natural supplement, reduced IL-8, IL-6, NF- $\mathrm{kB}$, and TNF- $\alpha$ mRNA transcripts in PBMC of 24 healthy volunteers after twice daily administration for 4 weeks. Reduction of CRP and IL-1b transcripts was also observed but did not reach statistical 
Table 5 Changes in health questionnaire

\begin{tabular}{|c|c|c|c|c|c|c|c|c|}
\hline \multirow[t]{2}{*}{ Symptom scale } & \multicolumn{5}{|c|}{$\begin{array}{l}\text { Percentage of participants having symptoms before } \\
\text { intervention (0-never, 1-occasionally, 2-occasionally } \\
\text { severe, 3-frequent, } 4 \text {-frequent severe) }\end{array}$} & \multicolumn{3}{|c|}{$\begin{array}{l}\text { Changes in the health status after } \\
\text { intervention }\end{array}$} \\
\hline & 0 & 1 & 2 & 3 & 4 & Same & Better & Worse \\
\hline Fever & 95 & 5 & 0 & 0 & 0 & 100 & 0 & 0 \\
\hline Chills & 95 & 0 & 0 & 5 & 0 & 100 & 0 & 0 \\
\hline Fatigue & 50 & 25 & 10 & 10 & 5 & 85 & 10 & 5 \\
\hline Headaches & 75 & 10 & 10 & 5 & 0 & 95 & 5 & 0 \\
\hline Muscle stiffness & 55 & 25 & 5 & 15 & 0 & 80 & 15 & 5 \\
\hline Loss of appetite & 90 & 0 & 10 & 0 & 0 & 90 & 5 & 5 \\
\hline Joint pain & 75 & 10 & 5 & 10 & 0 & 85 & 15 & 0 \\
\hline Joint stiffness & 75 & 10 & 10 & 5 & 0 & 80 & 20 & 0 \\
\hline Constipation & 80 & 10 & 5 & 5 & 0 & 85 & 10 & 5 \\
\hline Diarrhea & 80 & 20 & 0 & 0 & 0 & 95 & 5 & 0 \\
\hline Bloating & 80 & 10 & 10 & 0 & 0 & 90 & 5 & 5 \\
\hline
\end{tabular}

significance. Subjects reported improvements in muscle and joint pains in quality of life questionnaire. Overall these data support the use of Infla-Kine supplementation as a means of decreasing chronic inflammation in otherwise healthy subjects.

\section{Authors' contributions}

NAM, SK, TEl, and NHR contributed to the design of the experiments. NAM performed experiments. NAM, SK, TEl, and NHR analyzed the experimental data, and wrote the publication. All authors read and approved the final manuscript.

\section{Author details}

${ }^{1}$ The Riordan Clinic, Wichita, KS, USA. ${ }^{2}$ Department of Translational Neuro-Oncology and Neuro-therapeutics, John Wayne Cancer Institute at Providence Saint John's Health Center, Santa Monica, CA, USA. ${ }^{3}$ Immune Advisors LLC, San Diego, CA, USA. ${ }^{4}$ Aidan Products, Dallas, TX, USA.

\section{Acknowledgements}

None.

\section{Competing interests}

NHR is a shareholder of Aidan Products, which manufactures Infla-Kine.

\section{Availability of data and materials}

All data generated or analyzed during this study are included in this manuscript. For any additional information, please contact the corresponding author.

\section{Consent for publication}

The manuscript does not contain any identifiable individual person's data in any form. The provided dataset is fully anonymous. All authors consent to publication of the manuscript.

\section{Ethics approval and consent to participate}

The study were performed in accordance with the ethical guidelines of the Helsinki Declaration and was approved by the Institutional Review Board of Riordan Clinic. Participants provided written informed consent before study enrollment.

\section{Funding}

This work was supported by Aidan Products, the manufacturer of Infla-Kine.

\section{Publisher's Note}

Springer Nature remains neutral with regard to jurisdictional claims in published maps and institutional affiliations.

Received: 7 August 2017 Accepted: 10 October 2017

Published online: 20 October 2017

\section{References}

1. Matsui Y, et al. Overexpression of TNF-alpha converting enzyme promotes adipose tissue inflammation and fibrosis induced by high fat diet. Exp Mol Pathol. 2014;97(3):354-8.

2. Shimizu T, et al. HMGB1 is secreted by 3T3-L1 adipocytes through JNK signaling and the secretion is partially inhibited by adiponectin. Obesity (Silver Spring). 2016:24(9):1913-21.

3. Vielma $S A$, et al. Adipocytes as immune regulatory cells. Int Immunopharmacol. 2013;16(2):224-31.

4. Hotamisligil GS, Spiegelman BM. Tumor necrosis factor alpha: a key component of the obesity-diabetes link. Diabetes. 1994;43(11):1271-8.

5. Hube F, et al. Expression pattern of tumour necrosis factor receptors in subcutaneous and omental human adipose tissue: role of obesity and non-insulin-dependent diabetes mellitus. Eur J Clin Investig. 1999;29(8):672-8.

6. Nieto-Vazquez I, et al. Insulin resistance associated to obesity: the link TNF-alpha. Arch Physiol Biochem. 2008;114(3):183-94.

7. Stephens JM, Lee J, Pilch PF. Tumor necrosis factor-alpha-induced insulin resistance in 3T3-L1 adipocytes is accompanied by a loss of insulin receptor substrate-1 and GLUT4 expression without a loss of insulin receptormediated signal transduction. J Biol Chem. 1997;272(2):971-6.

8. Zubkova ES, et al. Regulation of adipose tissue stem cells angiogenic potential by tumor necrosis factor-alpha. J Cell Biochem. 2016;117(1):180-96.

9. Wong MM, et al. Macrophages control vascular stem/progenitor cell plasticity through tumor necrosis factor-alpha-mediated nuclear factorkappaB activation. Arterioscler Thromb Vasc Biol. 2014;34(3):635-43.

10. Mao A, et al. Modulation of the number and functions of endothelial progenitor cells by interleukin 1 beta in the peripheral blood of pigs: involvement of p38 mitogen-activated protein kinase signaling in vitro. J Trauma Acute Care Surg. 2012;73(5):1145-51.

11. Lapidos KA, Sprague SM, Ameer GA. Impact of serum source and inflammatory cytokines on the isolation of endothelial colony-forming cells from peripheral blood. J Tissue Eng Regen Med. 2014;8(9):747-56. 
12. Cohen KS, et al. Circulating CD34(+) progenitor cell frequency is associated with clinical and genetic factors. Blood. 2013;121(8):e50-6.

13. Xiao Q, et al. Endothelial progenitor cells, cardiovascular risk factors, cytokine levels and atherosclerosis - results from a large populationbased study. PLoS ONE. 2007;2(10):e975.

14. Dmitrieva OS, et al. Interleukins 1 and 6 as main mediators of inflammation and cancer. Biochemistry (Mosc). 2016;81(2):80-90.

15. Khan $\mathrm{S}$, et al. Chronic inflammation and cancer: paradigm on tumor progression, metastasis and therapeutic intervention. Gulf J Oncol. 2016;1(20):86-93.

16. Hammam O, et al. A Possible role for TNF-alpha in coordinating inflammation and angiogenesis in chronic liver disease and hepatocellular carcinoma. Gastrointest Cancer Res. 2013;6(4):107-14.

17. Naldini A, Carraro F. Role of inflammatory mediators in angiogenesis. Curr Drug Targets Inflamm Allergy. 2005;4(1):3-8.

18. Landskron $\mathrm{G}$, et al. Chronic inflammation and cytokines in the tumor microenvironment. J Immunol Res. 2014;2014:149185.

19. Panichi $V$, et al. Biomarkers of chronic inflammatory state in uremia and cardiovascular disease. Int J Inflamm. 2012;2012:360147.

20. Simmons EM, et al. Plasma cytokine levels predict mortality in patients with acute renal failure. Kidney Int. 2004;65(4):1357-65.

21. Kaysen GA, Eiserich JP. Characteristics and effects of inflammation in endstage renal disease. Semin Dial. 2003;16(6):438-46.

22. Chauveau $P$, et al. C-reactive protein and procalcitonin as markers of mortality in hemodialysis patients: a 2-year prospective study. J Ren Nutr. 2003;13(2):137-43.

23. Panichi $\vee$, et al. C-reactive protein as a marker of chronic inflammation in uremic patients. Blood Purif. 2000;18(3):183-90.

24. Furtado M, Katzman MA. Neuroinflammatory pathways in anxiety, posttraumatic stress, and obsessive compulsive disorders. Psychiatry Res. 2015;229(1-2):37-48.
25. Vogelzangs $\mathrm{N}$, et al. Anxiety disorders and inflammation in a large adult cohort. Transl Psychiatry. 2013;3:e249.

26. Matsuzaki T, Chin J. Modulating immune responses with probiotic bacteria. Immunol Cell Biol. 2000;78(1):67-73.

27. Mikirova NA, et al. Nutraceutical augmentation of circulating endothelial progenitor cells and hematopoietic stem cells in human subjects. J Transl Med. 2010;8:34.

28. Uccelli A, Moretta L, Pistoia V. Mesenchymal stem cells in health and disease. Nat Rev Immunol. 2008;8(9):726-36.

29. Pepys MB, Hirschfield GM. C-reactive protein: a critical update. J Clin Investig. 2003;111(12):1805-12.

30. Marsik C, et al. C-reactive protein and all-cause mortality in a large hospital-based cohort. Clin Chem. 2008;54(2):343-9.

31. Bonomini F, Rodella LF, Rezzani R. Metabolic syndrome, aging and involvement of oxidative stress. Aging Dis. 2015;6(2):109-20.

32. Zulet MA, et al. Inflammatory biomarkers: the link between obesity and associated pathologies. Nutr Hosp. 2007;22(5):511-27.

33. Ghanim $\mathrm{H}$, et al. Circulating mononuclear cells in the obese are in a proinflammatory state. Circulation. 2004;110(12):1564-71.

34. Wihastuti TA, et al. Level of circulating endothelial cells and expression of nuclear factor kappa beta of human's peripheral blood mononuclear cells in subjects with certain conditions. Acta Med Indones. 2014;46(1):30-7.

35. Lucas $R$, et al. Cytokine profiling of young overweight and obese female African American adults with prediabetes. Cytokine. 2013;64(1):310-5.

36. Munoz A, Costa M. Nutritionally mediated oxidative stress and inflammation. Oxidative Med Cell Longev. 2013;2013:610950.

\section{Submit your next manuscript to BioMed Central and we will help you at every step:}

- We accept pre-submission inquiries

- Our selector tool helps you to find the most relevant journal

- We provide round the clock customer support

- Convenient online submission

- Thorough peer review

- Inclusion in PubMed and all major indexing services

- Maximum visibility for your research

Submit your manuscript at www.biomedcentral.com/submit

BioMed Central 